\title{
ENTRE O SENTIMENTO RELIGIOSO E O RA- CIONAL: EXPERIÊNCIA DE ESTÁGIO SOBRE O POVO HEBREU E INDEPENDÊNCIA DOS ESTA- DOS UNIDOS
}

\section{BETWEEN RELIGIOUS AND THE RATIONAL FEELING: STAGE EXPERIENCE ABOUT THE HEBREW PEOPLE AND INDEPENDENCE OF THE UNITED STATES}

Gabriel Irinei Covalchu ${ }^{1}$

Resumo: Este trabalho é resultado do estágio supervisionado, realizado em Bituruna-Paraná, na instituição de ensino, Colégio Estadual Santa Barbará, durante o ano letivo de 2017, nas séries do ensino fundamental e médio sob supervisão do professor Gerson Luís Lanzarini. Os temas selecionados para serem trabalhados em sala foram: Povo Hebreu $\left(6^{\circ}\right.$ ano) e Independência dos Estados Unidos ( $2^{\circ}$ ano). Busco mostrar através da experiência em sala e os resultados obtidos nas avaliações, como o professor deve tentar o máximo possível ser imparcial e levar a sala para uma época distante para entender melhor o contexto, sendo necessário deixar nula a sua perspectiva de contra ou a favor em determinados fatos para uma melhor aprendizagem do aluno e o desenvolvimento da 'consciência histórica'. Também busco mostrar como as normas do NRE (Núcleo Regional de Educação), no caso a recuperação concomitante afeta no conteúdo em sala de aula; essa "ajuda" é para que o aluno venha compreender melhor a matéria ou apenas pelos índices?

Palavra-chave: Estágios; Educação; Docência. Ensino de História.

\footnotetext{
${ }^{1}$ Acadêmico do $4^{\circ}$ ano do Curso de Licenciatura em História da UNESPAR, Campus de União da Vitória-PR e Bolsista de Iniciação Científica da Fundação Araucária de Apoio ao Desenvolvimento Científico e Tecnológico, vinculado ao projeto Linguagens e Tecnologias no Ensino de História, desenvolvido pelo LAPHIS sob orientação da professora Dulceli de Lourdes Tonet Estacheski e do professor Everton Carlos Crema.
} 
Abstract: This work is the result of a supervised internship, held in Bituruna-Paraná, at the teaching institution of the State School of Santa Barbará, during the academic year 2017, under the supervision of teacher Gerson Luís Lanzarini. The subjects selected to be worked in the room were: Hebrew (6th year) and United States (2nd year). The subjects selected to be worked in the room were: Hebrew People (6th year) and United States Independence (2nd year). I seek to show through the experience in the room and the results obtained in the evaluations, as the teacher should try as much as possible to be impartial and take the room to a distant epoch to better understand the context, being necessary to leave void its perspective of against or in favor in certain facts for better student learning and the development of 'historical consciousness'. I also try to show how the NRE (Regional Education Core) standards, in the case of concomitant recovery, affect the content of the classroom; this "help" is for the student to better understand the subject or just by indexes?

Keyword: Stages; Education; Teaching; History teaching.

\section{Introdução}

Este trabalho tem como objetivo mostrar os resultados do estágio (matéria obrigatória para a conclusão do curso de história na Universidade Estadual do Paraná - campus de União da Vitória), realizado no Colégio Estadual Santa Barbará durante o ano letivo de 2017, as aulas foram realizadas sob a supervisão do professor efetivo de história da instituição, Gerson Luís Lanzarini e somaram um total de doze, sendo distribuídas seis em cada turma. Os seguintes temas foram selecionados para serem trabalhados: Povo Hebreu ( $6^{\circ}$ ano) e Independência dos Estados Unidos ( $2^{\circ}$ ano).

Meu objetivo em sala de aula era que os alunos além de entenderem a matéria, pudessem desenvolver a consciência histórica, ou seja, 
que eles conseguissem "analisar o passado, problematizar o presente e perspectivar o futuro" (RÜSEN, 2007, p.10), não apenas limitar-se no compreender ou ter uma noção de como funcionava determinadas épocas ou período, afinal de contas, o que muda ele saber ou não de um povo que teve início em Ur dos Caldeus e perambulou 40 anos no deserto até entrar em Canaã? Ou de um povo que se rebelou contra as duras ações impostas pela metrópole sobre a colônia e realizou uma independência? O conhecimento não deve limitar-se ao estudo do passado, mas devendo expandir no estabelecimento de uma relação passado/presente. Nesse sentido, o estudante pode relacionar esse conteúdo aprendido, com a sua vida cotidiana, ou seja, seria um "saber" para problematizar a sua própria realidade e perspectivar o futuro, pois só entender o passado não basta.

\section{Ensino de História}

Busquei o máximo possível que os alunos dialogassem na aula, no sexto ano essa prática foi realizada com êxito, já no segundo nem tanto, mas primeiramente vamos entender uma historiografia que utilizei para chegar à conclusão que uma aula expositiva dialogada faria com que os estudantes entendessem melhor essa relação passado/presente.

Durante muito tempo o ensino foi fechado apenas no professor, sendo ele o 'suprassumo' de todo o conhecimento, ignorando totalmente o conhecimento prévio do estudante. A história positivista ressaltava apenas os grandes feitos, datas, heróis e só tinham valia os documentos oficiais. Essa realidade só começou a mudar, quando a Escola dos An- 
nales em 1920, começou a utilizar outras tipologias de fontes, como a arqueológica, e não apenas os documentos escritos. $\mathrm{O}$ foco era pensar historicamente e não travar no passado, trazendo assim, uma história problema, deixando a linearidade de lado.

Como principal embasamento de minha postura como o adulto da sala, usufruí de uma obra de Paulo Freire, intitulada Pedagogia da Autonomia (1987), que foi trabalhada com maestria no meu segundo ano na matéria didática da história. No primeiro capítulo Freire nos mostra uma simples, mas profunda reflexão; "não há docência sem discência" (FREIRE, 1987, p.12), pois o mesmo defende um ensino que consiga desenvolver a criticidade dos alunos, e em contrapartida chamando o tradicionalismo da escola brasileira de "educação bancária", que ocorre quando o professor ou a professora ignoram a autonomia do pensar desse discente e "vomitam" conteúdo sobre o mesmo.

Freire (1987) propunha a construção do saber de forma conjunta, entendendo que os estudantes seriam capazes de ter o espaço para questionar os novos saberes, tanto que além de muitas tarefas e subtítulos de sua obra, uma que me chama a atenção é "ensinar exige disponibilidade para o diálogo", uma aula somente expositiva além de ser chata, o aluno (a) não consegue relacionar com sua realidade, mas quando abre espaço para o mesmo questionar e desenvolver a sua criatividade, o resultado é excepcional.

O que busco mostrar é o professor/professora reconhecendo seu o papel de extrema importância para que a aula seja "boa", o exercício do poder está na mão do docente, mas muitas vezes só ele/ela que fala e 
não abre espaço para o estudante expressar-se, tanto que um dos pontos defendidos por Freire, é que ensinar exige saber escutar, afinal de contas "não há saber mais, nem saber menos, há saberes diferentes" (FREIRE, 1987, p.68).

\section{Como avaliar?}

Estabelecidos certos métodos de interação entre professor/estudante, é necessário estabelecer métodos avaliativos, analisando tanto a prática docente quanto a discente, para isso, as atividades avaliativas tiveram base na obra de Vasco Pedro Moretto, "Prova: um momento privilegiado de estudo, não um acerto de contas (2008)". Na obra citada, o autor aborda frases que a maioria já deve ter ouvido, como por exemplo, "anotem, pois vai cair na prova", "Se não ficarem calados vou fazer uma prova-surpresa", fora alguns professores e professoras altamente preocupados(as) com o aprendizado do discente, afirmando sentenças como, "se vocês não prestarem a atenção não tem problema, meu salário está na conta final de mês" ou "quem precisa disso é vocês, eu já possuo o conhecimento, estou nem ai", são essas frases que nos levam a problematizar essa avaliação "da hora do acerto de contas".

Essa prova no sentido de acertar as contas, não consegue fazer o estudante entender o processo de aprendizagem e perceber-se como agente histórico, pelo contrário ele tentará decorar a matéria para agradar o professor ou a professora, ignorando a avaliação como um momento privilegiado de estudo. 
O fato de o aluno decorar e não aprender é algo mais complexo do que se apresenta, pois muitas vezes a consequência desse ponto são perguntas mal elaboradas, que não visam uma problematização do conteúdo e nem o desenvolvimento da sua consciência histórica, como é citado pelo texto de Moretto (2008), um aluno reivindicava nota máxima por uma questão que o professor havia zerado; sendo que o mesmo era merecedor de tal petição, devido à pergunta ser formulada de forma abrangente. Existem exemplos que são até mesmo publicados na mídia digital, onde o professor ou a professora faz uma questão para um aluno (a) do $6^{\circ}$ ano, "com o que se parece a metade de uma maça?", e a resposta é 'com a outra metade' e tem a questão zerada, no entanto, a pergunta não buscava uma resposta elaborada e sim uma 'decoreba' sem sentido, que não muda nada na vida do estudante. Falo por experiência própria, pois quando estava no segundo ano de ensino médio, em uma prova do segundo bimestre, a professora de filosofia colocou a seguinte questão: "deixe sua opinião sobre os monges copistas" e minha resposta foi "eles eram importantes por que escreviam em uma época que ninguém sabia escrever" e tive a resposta zerada, pois a professora desejava outra, é de fácil percepção que a pergunta era relativa a um contexto e mal elaborada, mas a professora esperava algo complexo.

As perguntas que utilizei nas minhas atividades avaliativas tiveram uma introdução historiográfica para facilitar o entendimento sobre a questão; o que Moretto (2008) chama de uma avaliação eficiente e eficaz, pois não busquei só a eficácia da prova, mas também a eficiência, para entender o que o próprio autor denomina de racional, econômico e 
útil. Fazer os alunos tirarem 10 na prova decorando datas e "heróis" faz sua avaliação eficaz, mas isso não quer dizer que foi eficiente, pois a eficiência avaliativa tem como objetivo a compreensão que os discentes entendam a relevância do contexto em sua vida e assim esse processo de aprendizagem será racional e útil, e não memorizado apenas.

A necessidade de entender a realidade social e o lugar social é de suma importância, Moretto (2008) nos mostra isso perfeitamente utilizando-se de uma piada que circula na internet, afirmando que houve uma pesquisa mundial desenvolvida pela ONU.

A ONU resolveu fazer uma grande pesquisa mundial. A pergunta era a seguinte: "Por favor, diga honestamente: qual sua opinião sobre a escassez de alimentos no resto do mundo?". O resultado foi um fracasso. Razões:

Os Europeus não entenderam o que era "escassez".

Os africanos não sabiam o que eram "alimentos".

Os argentinos não sabiam o significado de "por favor".

Os norte-americanos perguntaram o significado de "o resto do mundo".

Os cubanos estranharam e pediram mais explicações sobre "opinião".

O Congresso brasileiro ainda está debatendo o que é "honestamente". (MORETTO, 2008, p.93)

Falar de fora do sistema é o que mais ocorre na atualidade, pessoas que nunca tiveram contato com a educação opinando e dizendo o que devemos ou não ensinar, ignorando uma realidade escolar, a individualidade de cada um, tanto que infelizmente é normal escutar até mesmo de pessoas que estão dentro do sistema educacional: "se o aluno Aureliano consegue, todos conseguem" a empatia é totalmente descartada 
nessa frase, o colocar-se no lugar do sujeito de fala ou do próprio estudante é uma ferramenta fundamental para o desenvolvimento do aprendizado, analisando e levando em consideração a realidade social do mesmo. Se frases como essa ocorrem dos próprios docentes imagine de pessoas que nunca estiveram dentro de uma sala de aula, que não escutaram uma frase como "minha única refeição é na escola" ou "passei a noite toda cuidando do forno de carvão ${ }^{2 "}$ e achar que isso não afeta no aprendizado, a educação é uma palavra complexa para pessoas que estão apenas na letra "E" pensar que dão conta de explicar todo esse processo.

O avaliar deve levar em conta não só a resposta, mas como é realidade do aluno, como está sendo esse processo de aprendizado e como ele sê vê no mesmo, buscando mostrar novos horizontes para os discentes. Para esse avaliar é necessário antes da atividade estabelecer certos critérios que são de suma importância para analisar essa aprendizagem. Estou vinculado ao projeto Linguagens e Tecnologias no ensino de história $^{3}$, financiado pela Fundação Araucária, onde em uma etapa do processo foi entrevistar os professores da rede estadual de ensino de União

${ }^{2}$ Frase que ouvi de um aluno do primeiro ano do ensino médio, quando dava aula em um determinado colégio de Bituruna - Paraná.

${ }^{3} \mathrm{O}$ projeto Linguagens e Tecnologias no ensino de história financiado pela Fundação Araucária de Apoio ao Desenvolvimento Científico e Tecnológico do Estado do Paraná, é vinculado ao LAPHIS (Laboratório de Aprendizagem Histórica), sob a coordenação do professor Everton Carlos Crema e da professora Dulceli de Lourdes Tonet Estacheski, pelo programa PIC (Projeto de iniciação científica) da UNESPAR (Universidade Estadual do Paraná), campus de União da Vitória. Temos como principal objetivo, através da pesquisa aplicada, compreender qual é o conhecimento do professor e da professora de história sobre as linguagens e tecnologias de ensino e como ele/ela articula seus usos em sala de aula. O projeto iniciado em $01 / 08 / 2017$, tem vigência até o dia $31 / 07 / 2018$. 
da Vitória - Paraná, em uma determinada pergunta é questionado sobre os critérios de escolha do livro didático, podemos analisar isso também em relação à avaliação, quais os critérios utilizados para a correção da mesma? Muitas vezes no avaliar das atividades são usadas "dois pesos e duas medidas", pois não tem parâmetros para corrigi-las. No meu plano de aula já estava inserido os métodos que usaria para analisar e aplicar a notas, que no caso seria a coerência na fala; Domínios de conteúdo; A capacidade crítica; Participação nas tarefas; Participação nos espaços pedagógicos de forma construtiva e organizada; Capacidade de autonomia, sem descartar a realidade social do aluno e esse processo de aprendizagem.

Não busco dizer que esse avaliar a realidade social do estudante é simplesmente pensar que mesmo ele não participando, não estudando, mas porque ele trabalha o dia todo, vou dar nota de graça, o que quero mostrar é que devemos analisar essa questão buscando conteúdos mais próximos da realidade do aluno, que o mesmo venha a sentir interesse em participar das atividades desenvolvidas em sala percebendo que é um sujeito histórico. O discente é humano e não uma máquina, assim como os docentes, tem momentos de paixões, brigas, tristezas, raivas, rancores, percas, dores, fome e etc.

\section{Relato de Experiência}

Vamos iniciar com o relato de experiência do sexto ano, basicamente meu objetivo era mostrar como se deu o início do monoteísmo e como o povo Hebreu se portou perante a moralidade desse Deus em que 
eles acreditavam, depois de compreendido esse ponto, tentar fazer com que os estudantes conseguissem estabelecer a relação passado/presente, ou seja, relacionar o início da religião monoteísta com o cristianismo atual, pensando na consciência histórica dos mesmos. A disciplina dos alunos era ótima e a participação era boa, muitos deles faziam ligação da matéria junto com o ensino catequético, que por serem católicas a frequentam.

Quando perguntei se os estudantes já haviam assistido algum filme relacionado à abertura do Mar Vermelho, a maioria disse que não, então resolvi mudar a estratégia para aproximar com a realidade da turma, e perguntei se todos haviam assistido o filme "O todo poderoso" (2003), a maioria respondeu de forma afirmativa, então comecei a refletir sobre a parte que o Bruce senta em uma lanchonete e pede uma sopa vermelha e "testa seu poder" como Deus abrindo-a, alguns lembraram e outros não, então levei para a sala o recorte do filme, o que aproximadamente demora um minuto e trinta e dois segundos.

A cena do filme era muito mais próxima da realidade da sala, então torna-se mais adequado ao ensino. Nesse mesmo sentido pensei em usar trechos do filme 'Êxodo: Deuses e Reis' (2014), mas como a maioria não havia assistido, resolvi usar uma indicação dos próprios estudantes, a novela da Record, "Os Dez Mandamentos (2015)”, o que funcionou perfeitamente.

Para eles entenderem como ocorre a diferença de um documento oficial e a "não-oficial", abordei um tema mais próximo da realidade dos discentes, mostrei as imagens reproduzidas pela mídia, que nem 
sempre são reais ou tem algum fundamento histórico, como diz o "ditado popular", não é porque está na internet que é uma verdade. Primeiramente ouvimos o Hino de Bituruna, que logo no início já declara "Quando os índios em tempo de outrora. Vagueavam por esta região, já anteviam os dias de agora. Pela força invulgar deste chão”. Segundamente mostrei como as fontes narram a morte de todos os índios Ibituruna de forma desumana e brutal; meu objetivo era mostrar que o historiador também oculta fatos de acordo com seu interesse, entendimento e narrativa. $\mathrm{O}$ iniciar com os índios Ibiturunas (realidade mais próxima), era para introduzir uma atividade sobre os Hebreus, mostrando a divergência entre fonte e reprodução. Primeiramente levei a passagem bíblica de Êxodo, capítulo 2, e do versículo um ao cinco.

E foi um homem da casa de Levi e casou com uma filha de Levi. E a mulher concebeu e deu à luz um filho; e, vendo que ele era formoso, escondeu-o três meses. Não podendo, porém, mais escondê-lo, tomou uma arca de juncos, e a revestiu com barro e betume; e, pondo nela o menino, a pôs nos juncos à margem do rio. E sua irmã postou-se de longe, para saber o que lhe havia de acontecer. E a filha de Faraó desceu a lavar-se no rio, e as suas donzelas passeavam, pela margem do rio; e ela viu a arca no meio dos juncos, e enviou a sua criada, que a tomou. (Êxodo 2:1-5 - BJFA - Bíblia João Ferreira Almeida) 


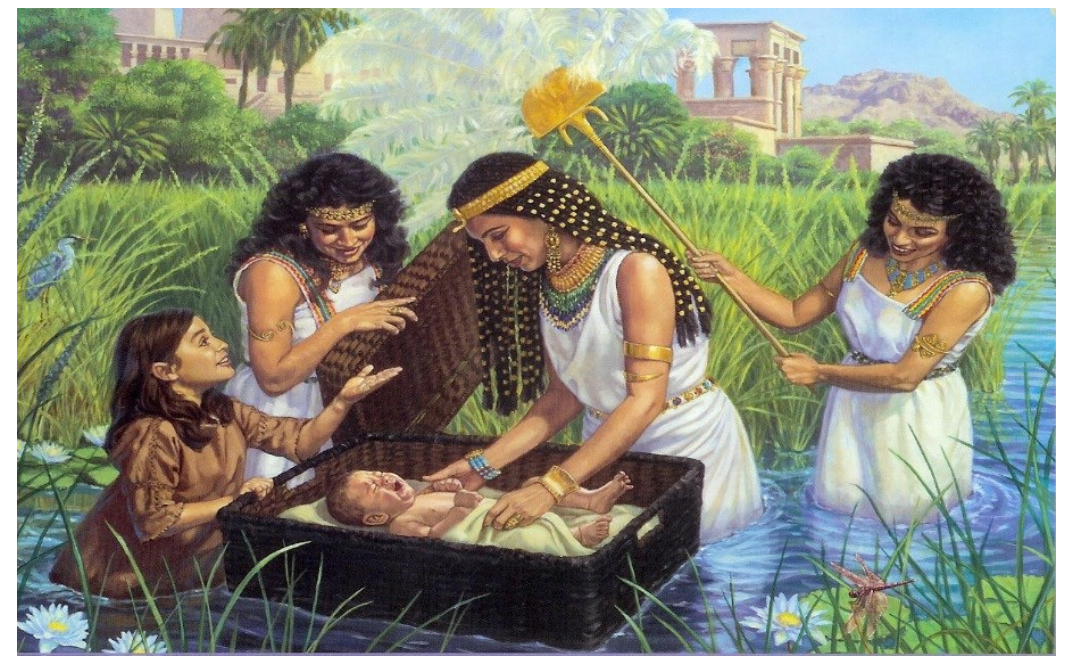

Imagem 1: Moisés encontrado no rio Nilo. Fonte: Gomes (2015)

Depois de ler a narrativa bíblica, expliquei o contexto, a necessidade que a mãe de Moisés teve em abandonar seu filho devido ao decreto de Faraó ${ }^{4}$, logo após, realizei algumas perguntas de forma oral, por exemplo, “a mãe de Moisés colocou ele qual local?”, “onde a irmã de Moisés ficou?", “quem encontrou Moisés”. Chamei atenção para alguns pontos específicos da passagem, como "margem" do rio; a filha de faraó que desceu para banhar-se; a postura da irmã de Moisés na narrativa, pois ela acompanha a maioria do processo de longe. Então levei a imagem acima para analisar em sala e também o trecho da novela selecionado por eles, mostrando as diferentes representações da fonte. Repare que Moisés não foi colocado no rio, mas sim à margem dele, e geral-

\footnotetext{
4 "Quando ajudardes as hebreias a darem à luz, observai as duas pedras. Se for menino matai-o. Se for menina, deixai-a viver". Bíblia de Jerusalém. São Paulo: Paulus, 2002, p.103.
} 
mente as imagens reproduzidas em desenhos ${ }^{5}$, filmes ou seriados é o mesmo totalmente inserido dentro do Nilo e percorre as águas parando perto do palácio de Faraó, ou seja, diferenças na interpretação da fonte e representação da mesma.

Para essa análise, eu utilizei apenas uma aula, visto que os trechos de filme eram curtos e a passagem bíblica era pequena, quando faltava 15 minutos de aula, solicitei a escrita do que foi aprendido em sala, tendo como objetivo a fixação do entendimento do conteúdo.

Com a averiguação das respostas dos discentes, consegui perceber que a influência religiosa é muito forte na vida deles e como consequência desse fato ocorre a dificuldade de se desprender da mesma para uma análise de conteúdo, pensando que tentar justificar algo pela razão seria um ataque a fé, como citei, busquei não colocar a minha crença para não atrapalhar essa análise, ressaltando que não devemos dizer se realmente foi 'milagre', mas que depende da crença de cada um, mesmo assim quando questionados "Com base nas aulas, material disponibilizado pelo professor e no livro didático, escreva sobre o início da história dos Hebreus", surgiram textos como o do aluno Constantino ${ }^{6}$ :

Essa grande história do povo Hebreu começa quando Abrãao se casa com Sara, uma mulher estéril, ou seja, não podia ter filhos. Mas como tinha muita fé em Deus pediu para que Ele a curasse. O Deus curou a e então teve um filho que era Isaque, que se casou com Rebeca que também era estéril. Mas Deus também curou ela, então ela teve

${ }^{5}$ Como o filme, Príncipe do Egito, 1998, produzido pela Dreamworks Animation. Levei um trecho desse filme de 2 minutos para exemplificar.

${ }^{6}$ Todos os nomes de alunos (as) utilizados no texto são fictícios. 
Esaú e Jacó que se casou com Lia e Raquel, tendo 12 filhos ao todo, e formaram as tribos de Israel, a partir daí a população só cresceu, no entendo foi parar no Egito, e Moisés foi levantado para libertar o povo mandando as 10 pragas, que eram para mostrar que Faraó não tinha mais poder que Deus. Depois de Moisés veio Josué, depois veio o governo dos Juízes e depois os reis, enfim é uma super matéria para estudar.

Repare que a fé do aluno está totalmente exposta no seu texto, lógico que não conseguimos deixar de lado nossas crenças na escrita, mas como historiador é necessário entender que o certo para mim, não é o certo para todos. No entanto também ocorreu narrativas como a do aluno Diocleciano

O povo Hebreu é monoteísta, ou seja, a crença em único Deus, e graças a eles que hoje tem o cristianismo, se não estaríamos adorando vários deuses, sempre devemos lembrar que todos os milagres realizados, vai da crença de cada um para saber se é verdade, pois não sabemos se realmente aconteceu.

Essa pergunta foi realizada na sexta aula (recuperação com 7 perguntas descritivas e 3 de marcar o X, impressa na folha A4), meu objetivo era além de fazer minha autocrítica, analisar se o conteúdo foi entendido pelos alunos. Alguns deles conseguiram entender a lógica das atividades, deixando claro que os acontecimentos "milagrosos" dependem da crença de cada um. Outros alunos "tomaram" minha fala e introduziram como uma visão unilateral, por exemplo, eu disse em sala, que segundo a crença judaico-cristã o objetivo de todas as pragas era mostrar a soberania de Deus sobre os deuses egípcios, o aluno Constan- 
tino tomou como uma verdade, já o Diocleciano mostrou que se foi providência divina ou não, depende da fé de cada um.

\section{Segundo ano}

No segundo ano do ensino médio, logo na primeira aula, fiz um 'resumo' do conteúdo, para depois voltar problematizando-o. Na segunda aula levei o material didático que eu mesmo produzi ${ }^{7}$, impresso, para o entendimento do processo de divisão das colônias, separação com a Inglaterra e a problematização desse contexto.

$\mathrm{Na}$ terceira aula ${ }^{8}$, separei a sala em três grupos, sendo o grupo 1 as colônias do sul, grupo 2 as colônias do norte e grupo três a Inglaterra. Cada grupo deveria escrever em apenas uma folha de caderno, para me entregar, argumentos para a independência ou permanência como colô-

${ }^{7} \mathrm{O}$ material didático, que foi produzido por mim, abordava o "Pacto Colonial", foi definições simples, mas buscava uma base para a atividade que seria proposta, basicamente o texto falava que o Pacto Colonial pode ser definido como um conjunto de regras, leis e normas que as metrópoles impunham às suas colônias durante o período colonial. Estas leis tinham como objetivo principal fazer com que as colônias só comprassem e vendessem produtos de sua metrópole. Através deste exclusivismo econômico, as metrópoles europeias garantiam seus lucros no comércio bilateral, pois compravam matérias-primas baratas e vendiam produtos manufaturados a preços elevados. O Pacto Colonial foi muito comum entre os séculos XVI e XVIII. As metrópoles proibiam totalmente o comércio de suas colônias com outros países ou criavam impostos tão altos que inviabilizava o comércio fora do pacto. O Pacto Colonial vigorou na relação entre a Inglaterra (metrópole) e suas colônias americanas (Estados Unidos). Inclusive, foi um dos principais motivos da revolta dos colonos americanos, que fomentou o processo de Independência dos Estados Unidos.

${ }^{8}$ Essa atividade foi realizada apenas em uma aula, pois seguindo a norma do NRE - Núcleo Regional de Educação, a quarta aula foi prova, quinta, realizado uma revisão de todo o conteúdo e na sexta a recuperação. 
nia, utilizando-se da explicação em aula, do material didático citado e o auxílio que o livro do PNDL $^{9}$ (Plano Nacional do Livro Didático), traz.

O grupo 1 usou o seguinte argumento.

Devido ao nosso clima propício, cultivamos coisas que não são possíveis cultivar na Inglaterra. E se ocorrer à independência não poderemos mais vender nossos produtos, pois eles não iriam comprar assim a população morreria de fome.

O grupo um conseguiu produzir uma consciência tradicional, demonstrando "recordar as origens e a repetição de obrigações, fazendo-o em forma de acontecimentos fática que demonstram o atributo de validade e obrigatoriedade dos valores e dos sistemas de valores" (RÜSEN, 2010, p.64).

Grupo 2

Somos capazes de exportar produtos florestais, peixes e peles com navios. Também utilizamos a produção e troca de mercadorias e comercializamos com outro ${ }^{10}$ regiões, somos capazes de liderar nossas colônia sozinhos.

O grupo dois conseguiu mostrar o que é a consciência exemplar e a crítica, que "nos ensina que curso de ação tomar e o que devemos evitar fazer" (RÜSEN, 2010, p.65), essas afirmações têm base nos próprios ingleses protestantes que vem para a colônia na tentativa de criar a "Nova Inglaterra" e trazem consigo as experiências da metrópole, analisado

\footnotetext{
${ }^{9}$ COTRIM, Gilberto. História Global 2. $3^{\mathrm{a}}$ Edição - São Paulo: Saraiva, 2016. ${ }^{10}$ Os erros ortográficos nas citações são dos próprios alunos, então decidi manter no original.
} 
pelo lado positivo, (industrialização, exportação). No caso da consciência crítica o grupo foi capaz de perceber que por se tratar de um pacto colonial e as colônias do norte que estão cada vez mais se industrializando desejam quebrar essas relações colônia/metrópole, criando argumentos que "são capazes de liderar suas colônias sozinhos".

\begin{abstract}
Grupo 3
$\mathrm{Eu}$, como representante da Inglaterra venho através deste esclarecer os motivos pelos quais as 13 colônias devem continuar sob o nosso poder. Primeiramente lembre-se de que, se vocês traírem a metrópole, estarão automaticamente traindo á Deus. Pois, foi ele quem ordenou a vocês fossem colônia, e se caso não cumprirem arcarão com as consequências. Nosso pacto não é para prendê-los, mas sim para deixá-los próximos á Deus.
\end{abstract}

O grupo três ficou convictamente na consciência tradicional, justificando com argumentos que estavam no imaginário da época, como previa o pacto colonial, pois como expliquei em sala de aula, um dos últimos pontos do pacto, afirmava que se desobedecessem a metrópole, estariam também desobedecendo a Deus, então usar argumentos que não busquem uma consciência crítica é de fundamental importância para não provocar sentimento de divisão nas colônias norte e sul.

Essa atividade eu pensei em tentar levar o imaginário dos alunos a "viver" no século XVIII. Depois de explicar todo o processo de divisão das colônias, problematizei mais a fundo as questões do social de época, como estava o sentimento religioso (protestantes imigrados da Inglater- 
ra), racional ${ }^{11}$ (ideais iluministas) e a consequência da Guerra dos Sete Anos. Ficou claro nos debates em sala, que assim como o historiador, os alunos também são tendenciosos e fazem a narrativa conforme seus interesses. Os alunos da sala que eram os "representantes" da Inglaterra, mostravam a legitimação por meio do ideal religioso, pois para suprir os déficits da guerra, necessitavam explorar as colônias. Os discentes do grupo das colônias do norte, afirmavam que conseguiriam viver tranquilamente sem precisar mandar impostos à coroa britânica, "o sonho da nova Inglaterra", idealizada pelos protestantes europeus. Os membros do grupo das colônias do sul (Virginia, Carolina do Norte e do Sul e Geórgia), analisaram o contexto de época e chegaram a conclusão que devido a serem exploradas pela Inglaterra, tinham que seguir o Pacto Colonial, caso ocorresse a divisão não conseguiriam sobreviver sem o apoio da Metrópole, pois eram baseados pelo latifúndio, monocultura, mão-de-obra escrava e sua exportação era apenas para a Inglaterra.

As respostas escritas da terceira aula já citadas, foram retomadas na quinta aula (revisão), em forma de debates, meu objetivo foi com que cada aluno "trocasse" os saberes com outro colega para conseguirem entender todo esse processo de independência dos Estados Unidos da América até a atualidade, para conseguir isso, fui norteando as perguntas inicias, como, "Por que os Estados Unidos são a maior potência capitalista da atualidade?"; "O que o livro do Cotrim narra sobre o Destino Manifesto", logo após fiz uma breve narrativa sobre a ascensão dos

\footnotetext{
${ }^{11}$ Por mais que no século XIX, na questão dos Estados Unidos, ocorre a justificativa da expansão por meio do "Destino Manifesto", o início da sua emancipação é legitimado por meio da razão.
} 
norte-americanos na Segunda Guerra Mundial. Quando chegou a recuperação (sexta aula), surgiram narrativas que considerei muito boa, como o texto da aluna Fausta em uma questão específica ${ }^{12}$ narrou:

Tudo começa quando ocorre a guerra dos sete anos, onde a Inglaterra perde muitos homens e começa a explorar muito a colônia. As colônias do norte começam a perceber que estão sendo exploradas em demasia e iniciam uma espécie de revolução, chegando até afundar navios de chá dos ingleses, enquanto o sul queria permanecer como colônia e vender seus produtos para a Inglaterra. Com o apoio da França e dos ideais iluministas os E.U.A conseguiram sua independência, e fundados como colônia de povoação e não exploração, aproveitando a segunda guerra, na atualidade são uma grande potência mundial, isso se reflete pela união das colônias, pelas ideias iluministas e puritanos.

\section{Resultados Obtidos}

Os resultados obtidos foram bons, mas eu esperava respostas mais detalhadas e mais críticas, talvez eu tenha falhado em minha metodologia. Lendo e relendo as avaliações, fiz o exame crítico da minha aula, percebo que no sexto ano passei desde a criação do mundo, segundo a crença dos hebreus, até o conflito entre o estado israelense e a Palestina atual, o que foi muito conteúdo para pouca aula (6). No entanto com as respostas e as participações em sala de aula era notável que os estudan-

${ }^{12}$ A pergunta era: De acordo com os trechos da obra discutida em sala, KARNAL, Leandro; FERNANDES, Luiz Estevam; MORAIS, Marcus Vinicius de; PURDY, Sean - História dos Estados Unidos: das Origens ao Século XXI, São Paulo: Contexto, 2007, o material didático "O Pacto Colonial e a persuasão Inglesa", o livro didático escrito por Cotrim (2016) e os debates em sala de aula, produza um texto sobre o processo de independência dos Estados Unidos e de forma resumida, como ele se tornou a potência capitalista da atualidade. 
tes estavam entendendo a matéria e conseguindo relacionar o processo de presente/passado. Poderia ter sido melhor trabalhado o conteúdo e de forma mais tranquila, pois ainda era necessário utilizar uma de minhas aulas para recuperação concomitante, seguindo a norma exigida pelo NRE, sendo assim é necessária uma revisão antes de aplicar a mesma.

Uma crítica que eu faço é se realmente tem a necessidade dessa recuperação ou é somente pelos índices que o NRE deve repassar a secretaria de educação? Segundo o Núcleo Regional de Educação, o professor deve ter no mínimo três notas, se existe três avaliações é necessário ter três recuperações. A disciplina de história no ensino médio tem apenas 20 aulas bimestrais, sendo que no mínimo, (pensando em apenas duas atividades avaliativas para registrar no $\mathrm{RCO}^{13}$ ), seis destas ficam fixas só para atividades avaliativas ${ }^{14}$, muitas vezes os alunos não têm a vontade de estudar para aprender a matéria, mas apenas para tirar nota, ainda mais com essa 'ajuda' das normas que vem sendo impostas, ignorando a autonomia do professor.

Voltando aos resultados, eu consegui perceber que o segundo ano teve um melhor desenvolvimento da consciência histórica, como foi mencionado nas páginas 9 e 10 . Os debates em sala de aula foram de grande relevância, mas como o tempo era apenas seis aulas, três eram

\footnotetext{
${ }^{13}$ Registro de classe online.

${ }^{14}$ Sendo os passos que devem ser seguidos, avaliação; revisão e recuperação. Lógico que toda aula possui algum tipo de avaliação, mas o sentido que falo é como a maioria dos meus professores fizeram e até hoje fazem, duas atividades escritas e duas recuperações escritas, devido a exigência do NRE.
} 
voltadas para atividade escrita, prova, revisão e recuperação isso dificultou um aprofundamento de todo o contexto.

Esses resultados poderiam ter sido melhores se não tivesse a necessidade de realizar a recuperação concomitante. No segundo ano pouquíssimas pessoas tiraram abaixo de 6,0 (média), se for para aplicar a recuperação concomitante só para quem está abaixo da média, as alunas acima da mesma ficam fazendo que tipo de atividade? Passar novo conteúdo e como consequência os que estão fazendo a recuperação ficam com a matéria atrasada? Ou seja, torna-se uma bola de neve. Percebo que se não necessitasse esses parâmetros de índices, o aprendizado seria melhor, e o professor analisando a realidade da turma sabe se realmente existe a necessidade da recuperação ou não.

\section{Considerações Finais}

Como o próprio título já diz ser professor é estar entre o sentimento religioso e o racional, entre a esquerda e a direita, ser professor é tentar o máximo possível ser imparcial para não afetar o aprendizado do aluno doutrinando-o. No estágio do sexto ano, tive que ser cuidadoso com as palavras, buscando sempre ressaltar que os fatos narrados, discutidos e problematizados eram segundo a crença do povo Hebreu, não que era fato verídico, isso dependia da fé de cada um. No estágio do segundo ano era totalmente o contrário, os ideais iluministas indo contra os religiosos, lógico que levamos em consideração o apoio dos puritanos em relação à educação, mas o que motivou a revolução foram os primeiros. Como tive experiência em sala prematuramente, já no segundo ano 
da minha graduação sendo professor PSS (Processo Seletivo Simplicado), percebi que o docente ao mesmo tempo que tem uma fé e uma absoluta crença em Deus para explicar a matéria e ficar de mais fácil entendimento para os alunos, de uma hora para a outra 'torna-se ateu' ${ }^{15}$ ou descrente no sistema religioso explicando o iluminismo, como dizia Raul Seixas, uma metamorfose ambulante.

O problema é que muitas vezes analisamos o passado com o olhar do presente, outras queremos impor nossas crenças para justificar certos fatos. O colocar nossa fé, ou nossos ideais que muitas vezes não auxiliam no aprendizado do estudante, pelo contrário, a narrativa unilateral doutrina-o e mata a consciência histórica do discente. Recordo que quando estava no ensino médio um professor de história disse que não deveriam existir cotas, afirmando que todos eram iguais e utilizando de falas que hoje as reconheço como discurso de ódio; eu só mudei essa visão quando no início do ano de 2017, quando meu professor de Brasil III $^{16}$, fez uma aula utilizando dados históricos e científicos sobre o assunto. A diferença do professor 1 para o professor 2, é o fato do segundo mostrar fontes e ter deixado a sala pensar e fazer a devida reflexão, enquanto o professor 1, impôs seu pensamento ignorando o debate e forçando uma visão unilateral de acordo com suas crenças.

\footnotetext{
${ }^{15}$ Sabemos que o professor não irá torna-se ateu e nem religioso, são apenas metáforas, afinal de contas, o conhecimento escolar não se pauta em crenças. $\mathrm{O}$ que o docente precisa, é saber situar estes pensamentos e sentimentos naqueles contextos para dar sentido histórico.

${ }^{16}$ Professor Doutor Ilton César Martins.
} 
São pequenas frases, pequenos gestos que mudam a mente do estudante, o correto é mostrar os dois ou mais lados da história e deixar que o mesmo decida se realmente aconteceu, ou seja, abordar uma fé absoluta para explicar as pragas, mas também mostrar o lado científico e como surgem as crenças. Levar para a sala os discursos religiosos e analisar com eles se a preocupação era somente com a fé ou se não era movida pela política; analisar uma revolução, mas sem esquecer quem são as pessoas que incentivam ela, e nunca generalizando, pois não são todos que aceitavam os padrões e os discursos de época, são coisas simples, mas que obtém resultados excelentes.

Esses resultados só tiveram importância para mim, graças a minha professora ${ }^{17}$ de estágio que nos acompanha desde o segundo ano na matéria de didática da história, pois me lembro de todos os conteúdos trabalhados em sala. Essa diferença foi de grande relevância na minha regência em todos os sentidos, inclusive ocorreu uma situação em especial; no início do ano letivo de 2017 a professora falou "valorize as coisas simples, as perguntas que parecem nada haver, mas que na realidade tem uma grande fundamentação na realidade do aluno e da aluna". A aluna Teodósia do sexto ano trouxe algumas moedas antigas do Brasil que foram da sua avó para a sala de aula, ou seja, uma atitude simples, como são crianças do sexto ano gerou aquele tumulto, pois todos queriam ver as moedas; naquele momento eu poderia "mandar" sentar, e dizer que não tinha nada a ver com o conteúdo que estávamos trabalhando e assim também matar toda a criatividade e vontade de participa-

${ }^{17}$ Dulceli de Lourdes Tonet Estacheski, que é a orientadora desse trabalho. 
ção da aluna junto, porém utilizei de gancho para entrar na parte econômica do povo Hebreu e como eles imaginavam as "moedas" daquele tempo, foi o "canal" para mudar o ambiente e o clima da turma.

$\mathrm{Na}$ sala de aula, nós podemos utilizar de pequenas coisas que parecem sem sentido e dar toda atenção, buscando que o estudante sinta-se parte daquela aula e de todo esse processo de aprendizagem, afinal de contas, não podemos mudar o mundo com a nossa aula, mas podemos mudar uma sala inteira, o que já é de extrema valia. Quando utilizo o termo mudar quero dizer o sentido de empatia, de liberdade de pensamento e de expressão, pois quando se colocamos nos lugares dos alunos, devemos parar para pensar se iríamos querer um professor que matasse nossa criatividade e anulasse a consciência histórica individual ou aquele que nos oferece autonomia e ajuda no desenvolvimento da nossa consciência histórica.

\section{Bibliografia}

Bíblia de Jerusalém. São Paulo: Paulus, 2002.

Bíblia Sagrada, trad. João Ferreira de Almeida. Edição Revista e Atualizada. Sociedade Bíblica do Brasil, 1959.

COTRIM, Gilberto. História Global 2. $3^{\text {a }}$ Edição - São Paulo: Saraiva, 2016.

FREIRE, Paulo. Pedagogia do oprimido. $17^{\mathrm{a}}$ ed. Rio de Janeiro, Paz e Terra, 1987.

MORETTO, Vasco Pedro. Prova: um momento privilegiado de estudo, não um acerto de contas -8 ed. Rio de Janeiro: Lamparina, 2008. 
RÜSEN, Jörn, Reconstrução do passado. In: Teoria da História II: Os princípios da pesquisa histórica. Tradução de Asta-Rose Alcaide. Brasília: Ed. Unb, 2007.

RÜSEN, Jörn. O desenvolvimento da competência narrativa na aprendizagem histórica: uma hipótese ontogenética relativa à consciencia moral. In: SCHMIDT, M. A.; BARCA, I.; MARTINS, E. R. (Orgs.). Jörn Rüsen e o ensino de História. Curitiba: Ed. UFPR, 2010.

SEFFNER, Fernando. Leitura e Escrita na História. In: SCHIMIDT, Maria Auxiliadora; CAINELLI, Marlene R. (orgs). III Encontro Perspectivas do Ensino de História. Curitiba: Aos quatro ventos, 1999.

Recebido em: 20/04/2018 Aceito em: 18/07/2018 